•研究报告・

\title{
水杉原生种群核心种质资源的繁殖特性
}

\author{
吴漫玲 ${ }^{1}$ 姚 兰 $^{1^{*}}$ 艾训儒 ${ }^{1}$ 朱 $^{1}$ 江 $^{1}$ 朱 强 $^{1}$

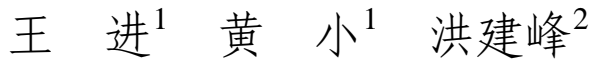

1 (湖北民族大学林学园艺学院, 湖北恩施 445000)

2 (星斗山国家级自然保护区管理局, 湖北恩施 445000)

摘要: 水杉(Metasequoia glyptostroboides)原生种群天然更新困难, 为探究其原因是否与繁殖特性有关, 本文以其 核心种质资源(40株个体)为对象，通过对生境、母树个体和种子性状的调查，并结合田间播种试验，分析其繁殖特 性。以方差分析检测不同母树个体间种子性状、发芽率和幼苗生长特征的差异; 采用相关性分析和多元线性回归 模型分析个体性状对其种子、发芽率及幼苗生长的影响; 通过Logistic模型拟合, 分析幼苗生长的节律参数。结果 显示: (1) 40 株母树个体仅有7株产种, 产种率仅为 $17.50 \%$, 且不同母树个体间产种量差异显著 $(P<0.05)$ 。(2)不同母 树个体间的种子千粒重、种子发芽率、幼苗存活率和基径生长量均存在显著差异 $(P<0.05)$ 。(3) 7 株母树个体种子 的平均发芽率为 $19.73 \%$, 幼苗平均存活率为 $73.42 \%$, 不同母树之间差异显著 $(P<0.05)$ 。(4)母树个体的胸径与种子 千粒重、种子发芽率呈显著负相关 $(P<0.05)$, 种子发芽率与幼苗存活率呈极显著正相关 $(P<0.001)$, 树高与幼苗存 活率呈显著正相关 $(P<0.05)$ 、与幼苗基径呈极显著正相关 $(P<0.001)$ 。(5)母树树高对幼苗存活率有显著正效应 $(P<$ $0.05)$, 胸径对种子发芽率有显著负效应 $(P<0.05)$ 。(6)苗高、基径的生长符合“S”型生长曲线 $\left(R^{2} \geq 0.928\right)$ 。水杉原 生种群产种量低, 种子发芽率低、幼苗存活率较低, 且不同母树之间差异显著可能是造成其天然更新困难的原因。 关键词: 水杉; 原生种群; 核心种质资源; Logistic模型

\section{The reproductive characteristics of core germplasm in a native Metasequoia glyptostroboides population}

\author{
Manling $\mathrm{Wu}^{1}$, Lan $\mathrm{Yao}^{1^{*}}$, Xunru $\mathrm{Ai}^{1}$, Jiang Zhu ${ }^{1}$, Qiang Zhu ${ }^{1}$, Jin Wang ${ }^{1}$, Xiao Huang ${ }^{1}$, Jianfeng Hong ${ }^{2}$ \\ 1 School of Forestry and Horticulture, Hubei Minzu University, Enshi, Hubei 445000 \\ 2 Administration Bureau of Xingdoushan National Nature Reserve, Enshi, Hubei 445000
}

\begin{abstract}
In order to explore the reproductive characteristics of Metasequoia glyptostroboides, we explored a native population of original Metasequoia glyptostroboides. We investigated the core germplasm of 40 individuals of native Metasequoia glyptostroboides and collected data on habitats, parent trees and seed traits. We used field experiment to analyze reproductive characteristics. We detected differences in seed traits, germination rate and seedling growth characteristics among different parent trees using ANOVA. The effects of individual traits on seeds, germination rate and seedling growth were analyzed with correlation and linear regression models. The results showed that: (1) There were only 7 strains from 40 mother trees, the seed yield rate was $17.50 \%$, and the difference in seed yield of 7 original mother trees was significant $(P<0.05)$. (2) There were significant differences in seed weight (1,000 grain), seed germination rate, seedling survival rate and base diameter growth among individuals of different parent trees $(P<0.05)$. (3) The average germination rate of seeds from seven mother trees was $19.73 \%$, and the average survival rate of seedlings was 73.42\% (inter-individual rates were also significantly different $(P<0.05)$. (4) Diameter at breast height (DBH) was negatively correlated with seed weight and germination rate $(P<0.05)$, while seed germination and seed weight $(P<0.05)$, seed germination and seedling survival $(P<0.001)$, and tree height and seedling survival $(P<0.05)$ were positively correlated. (5) The height of mother tree was positively correlated to
\end{abstract}

收稿日期: 2019-06-12; 接受日期: 2019-08-14

基金项目: 国家重点研发计划(2016YFC0503100)“极小种群野生植物种质资源保护技术研究与示范”课题(2016YFC0503102)、湖北民族大学博士启动 基金(MY2018B027)和湖北省自然科学基金(2019CFB229)

* 通讯作者 Author for correspondence. E-mail: 24752851@qq.com 
seedling survival rate $(P<0.05)$, and DBH was negatively correlated to seed germination rate $(P<0.05)$; and (6) Seedling growth (height and base diameter) conforms with logistic growth $\left(R^{2} \geq 0.928\right)$.

Key words: Metasequoia glyptostroboides; original population; core germplasm; Logistic growth

水杉(Metasequoia glyptostroboides)为杉科水杉 属植物, 是第四纪冰川子遗物种, 有植物界“活化 石”之称, 在《中国植物红皮书》中被列为国家I级 保护植物，且被世界自然保护联盟(International Union for Conservation of Nature, IUCN)列为极危等 级(https://www.iucn.org/)。水杉的发现被公认为是20 世纪我国乃至世界植物界的重大事件(胡先骕和郑 万钧, 1948), 其原生种群对研究古植物学、演化生 物学、古气候学、古地理学和地质学以及裸子植物 系统发育等方面具有十分重要的价值。

现存水杉原生种群分布在湖北利川、湖南龙 山、重庆石柱之间的三角区域内, 呈散生或小集群 分布。Chu和Cooper (1950)对利川水杉坝的水杉群 落进行调查研究时, 发现林下有大量的幼苗和幼树, 以此推断水杉种群在一段时间内可以稳定发展。然 而, 李建华和班继德(1989)发现水杉种群的分布格 局表现为随机分布, 受人为干扰严重, 群落结构简 单, 林下缺少幼苗和幼树。尤冬梅等(2008)发现很多 水杉原生群落林下种植了玉米(Zea mays)和黄连 (Coptis chinensis)等作物, 这些作物严重破坏了水 杉林下的原生环境, 使得水杉天然更新困难。林勇 等(2017)发现水杉原生母树年龄结构分布不均, 呈 现出“倒金字塔”形, 缺少幼苗和幼树, 自然更新极 差。因此, 水杉原生种群的自然更新障碍及人工繁 殖关键技术逐渐成为学术界关注的重点, 有众多学 者对水杉自然更新困难的原因开展了探索与研究。 如, 华东师范大学近几年研究了水杉自然更新、交 配系统与扩散格局、野生种群遗传多样性的时空格 局和种质资源保护 ${ }^{\mathbb{1} 2(3)}$ 。李庆梅等(2008)发现, 球果 和种子是物种繁殖系统的最重要组分, 处于强大的 选择压力下, 有很大的生态适应性, 它们同时也受 到较强的遗传控制, 最具有区分和比较的意义。另 外, 过去几十年, 国内外学者对水杉种子萌发也做 过大量的研究, 例如水杉种子的储藏方式(景丹龙 等, 2011)、硒元素对水杉种子萌发的影响(郭秋菊等, 2018)、水杉种子的生理生态(辛霞等, 2004)、枯落 物覆盖对水杉种子萌发的影响(尤冬梅和马广礼, 2008)、以及地下水位、埋藏深度和光照对水杉种子
萌发和幼苗生长的影响 ${ }^{(1)}$ 等。但水杉栽培引种区种 子活力差, 遗传多样性低(Kuser et al, 1997; 李晓东 等, 2003), 遗传多样性的丧失会造成物种趋向灭绝 (李媛媛, 2006), 只有现存的水杉原生母树种群保留 着最完整的基因库 ${ }^{5}$ 。

截至目前, 尚未有研究对原生种群的繁殖特性 进行详细分析。鉴于水杉原生种群所含的遗传信息 对于种群恢复和维持的重要性, 本文针对原生种群 核心种质资源母树开展繁殖特性的研究，以期从水 杉原生种群繁殖特性的角度，分析和阐明其产种、 发芽、幼苗生长与存活这一段生活史的规律，以验 证导致水杉原生种群自然更新困难的原因是否与 母树产种量少、种子质量差、种子发芽率低、幼苗 存活率低等有关, 为进一步获取水杉原生种群天然 更新困难的原因和致危机制提供参考和借鉴。

\section{材料与方法}

\section{1 原生母树性状调查}

水杉原生种群现存地理坐标为 $29^{\circ} 44^{\prime}-30^{\circ} 39^{\prime} \mathrm{N}$, $108^{\circ} 21^{\prime}-109^{\circ} 18^{\prime} \mathrm{E}$ ，海拔800-1,500 m。该地属热带 季风湿润性山地气候, 年均降水量 $1,500 \mathrm{~mm}$, 集中 在5-9月，占全年降水的70\%以上。夏季极端高温为 $35^{\circ} \mathrm{C}$, 冬季极端低温约为 $-5^{\circ} \mathrm{C}$, 平均气温为 $22^{\circ} \mathrm{C}$ 左 右。天然水杉群落 $80 \%$ 集中在以利川市小河地区为 中心的山谷地带, 地形为马蹄形盆地, 南北长约 $30 \mathrm{~km}$, 东西宽约 $20 \mathrm{~km}$, 区域内溪流密布。土壤多 为黄壤和黄棕壤。2017-2018年间对利川市境内现 存的5,663株水杉原生母树个体进行年龄、胸径、树 高、冠幅, 以及周围30 m范围内的房屋、农田、道 路等指标进行测量和调查。

(1) 刘玉配 (2015) 濒危物种水杉(Metasequoia glyptostroboides)自然种 群的更新限制研究. 硕士学位论文, 华东师范大学, 上海.

(2) 陈文文 (2016) 水杉(Metasequoia glyptostroboides)自然种群交配系 统和扩散格局研究. 硕士学位论文, 华东师范大学, 上海.

(3) 王思思 (2017) 水杉野生种群遗传多样性的时空格局及种质资源保 护. 硕士学位论文, 华东师范大学, 上海.

(4) 张岗 (2011) 水杉种子萌发和幼苗生长特性的研究. 硕士学位论文, 华中师范大学, 武汉.

(5) 崔敏燕 (2011) 濒危物种水杉种群的引种和生存力分析. 硕士学位 论文, 华东师范大学, 上海. 


\section{2 核心种质资源的确定}

华东师范大学陈小勇教授课题组在2017年对 3,000份水杉原生母树个体的活体样本通过微卫星分 子标记, 以等位基因差异篮选出40株核心种质资源。

\section{3 球果及种子样本采集与性状测定}

40株水杉母树中, 仅有7株产种, 个体编号分 别为 $0723 、 1011 、 4534 、 4541 、 5685 、 5705$ 和5741。 采集全部新鲜球果及时带回实验室, 计算每株母树 的新鲜球果产量, 同时测定每株母树的球果千粒 重。然后将球果置于阳台上阴干至种子完全从球果 中脱离, 测定每株母树种子产量及其种子千粒重。 球果千粒重和种子千粒重采用精度为万分之一的 电子天平测定, 每组数据3个重复。

\section{4 田间播种及幼苗性状的测量}

2018年4月初, 在利川市林业科学研究所实验 基地 $\left(108^{\circ} 5^{\prime} 12^{\prime \prime} \mathrm{E}, 30^{\circ} 16^{\prime} 1^{\prime \prime} \mathrm{N}\right)$ 开展田间播种试验, 基地海拔 $1,120 \mathrm{~m}$, 土壤为山地黄壤。在大田中选取 地面平缓的区域, 依次进行除草、整地和杀菌。按 不同母树个体分开播种, 将种子均匀撒播在地表, 播种密度为 3 粒 $/ \mathrm{cm}^{2}$, 然后在种子上面铺一层细土 (颗粒大小 $2-3 \mathrm{~mm}$ ), 厚度约为 $2 \mathrm{~mm}$, 再在上面均匀 地覆盖一层稻草, 厚度约为 $5 \mathrm{~mm}$, 遮盖率达到 $80 \%$ 以上。完成后, 浇水使土壤和稻草湿透。

种子出苗后, 在田垄中随机设置 3 个 $30 \mathrm{~cm} \times$ $30 \mathrm{~cm}$ 的样框, 将嵌入框内的种苗计数, 计算发芽 率。之后, 每15 d调查1次, 根据存活的幼苗数量计 算存活率; 在每个样框中随机抽取10株幼苗进行苗 高和基径测定, 获得幼苗生长指标。种子发芽率和 幼苗存活率计算公式如下:

$$
\begin{aligned}
& \text { 发芽率: } G r=\frac{G a}{G n} \times 100 \% \\
& \text { 存活率: } S R=\frac{N s}{G a} \times 100 \%
\end{aligned}
$$

式中, $G a$ 为发芽种子数量, $G n$ 为播放种子数量, $N s$ 为幼苗存活数量。

\section{5 数据处理与分析}

利用单因素方差分析(one-way ANOVA)比较不 同母树个体的种子、幼苗性状的差异; 采用相关性 分析和多元线性回归模型分析个体性状对其种子 发芽率及幼苗生长的影响; 采用SPSS 22.0对7个水 杉母树幼苗的苗高、基径生长节律数据进行Logistic 模型拟合(李峰卿等, 2018), 分析7个母树幼苗生长
节律参数。

Logistic模型拟合方程为:

$$
y=\frac{k}{\left(1+\mathrm{e}^{a-b t}\right)}
$$

式中, $y$ 为幼苗苗高累计生长量, $k$ 为拟合苗高的极限 值, $t$ 为生长时间, $a$ 和 $b$ 为待定系数。

参照杨志玲等(2011)的方法计算水杉不同母树 幼苗苗高、基径生长节律参数, 生长节律参数包括 物候期参数和生长参数。其中, 物候期参数包括线 性生长始期 $\left(t_{1}\right)$ 、线性生长末期 $\left(t_{2}\right)$ 和线性生长期 $(L G D)$, 生长参数包括最大线性生长速率 $(M G R$, 即 连日生长量最大时的生长速率)、线性生长速率 ( $L G R$, 即线性生长期内的平均生长速率)、线性生长 量(TLG, 即线性生长期内的生长量)和线性生长量 占总生长量的百分率。公式如下:

$$
\begin{aligned}
& t_{1}=\frac{(a-1.317)}{b} \\
& t_{2}=\frac{(a+1.317)}{b} \\
& L G D=\frac{2 \ln (2+\sqrt{3})}{4}=\frac{2.634}{b} \\
& M G R=v_{\text {max }}=\frac{1}{4} b k \\
& L G R=\frac{2}{9} b k \\
& T L G=\frac{k}{\sqrt{3}}
\end{aligned}
$$

\section{结果}

\section{1 母树个体及其繁殖性状特征}

调查的 40 株母树个体主要分布在海拔 1,000 1,300 m范围内, 大部分沿河流、水沟分布, 基本处 于山体的中下部或山谷地带, 且有人为活动的干扰 (表1)。其中, 仅有7株产种, 产种率仅为 $17.50 \%$; 这 7株个体的年龄范围为75-160年，平均年龄107年， 变异系数为 $33.19 \%$; 种子平均发芽率为 $19.73 \%$, 变 异系数为 $25.95 \%$, 幼苗平均存活率为 $73.42 \%$ (表2)。

\section{2 母树个体性状与繁殖特性的关系}

母树树高与幼苗存活率和基径呈显著正相关, 母树胸径与种子发芽率呈显著负相关 $(P<0.05)$ (表 3)。多元回归分析显示, 母树树高对幼苗的存活率 和基径有显著正效应，树高增加，幼苗的存活率和 基径也随之增加; 母树胸径对种子发芽率有显著负 
表140株水杉原生母树个体性状特征及产种情况

Table 1 Characteristics of individual traits and seed production of 40 Metasequoia glyptostroboides original mother trees

\begin{tabular}{|c|c|c|c|c|c|c|c|c|c|}
\hline $\begin{array}{l}\text { 原始编号 } \\
\text { Mother } \\
\text { tree no. }\end{array}$ & $\begin{array}{l}\text { 包含等位 } \\
\text { 基因个数 } \\
\text { Number of } \\
\text { alleles* }\end{array}$ & $\begin{array}{l}\text { 分布特点 } \\
\text { Distribution } \\
\text { characteri- } \\
\text { stics }\end{array}$ & $\begin{array}{l}\text { 树高 } \\
\text { Tree } \\
\text { height } \\
\text { (m) }\end{array}$ & $\begin{array}{l}\text { 胸径 } \\
\text { Diameter at } \\
\text { breast height } \\
(\mathrm{cm})\end{array}$ & $\begin{array}{l}\text { 冠幅 } \\
\text { Crown } \\
\text { diameter } \\
\left(\mathrm{m}^{2}\right)\end{array}$ & $\begin{array}{l}\text { 海拔 } \\
\text { Altitude } \\
\text { (m) }\end{array}$ & $\begin{array}{l}30 \mathrm{~m} \text { 范围内环境因素 } \\
\text { Environmental factors } \\
\text { within } 30 \mathrm{~m}\end{array}$ & $\begin{array}{l}\text { 2017年产种量 } \\
\text { Yield in } 2017\end{array}$ & $\begin{array}{l}\text { 备注 } \\
\text { Remarks }\end{array}$ \\
\hline 0628 & 11 & $\begin{array}{l}\text { 集群 } \\
\text { Cluster }\end{array}$ & 26 & 85.67 & 56.72 & 1,110 & $\begin{array}{l}\text { 道路、水沟 } \\
\text { Road and ditch }\end{array}$ & $\begin{array}{l}\text { 未产种 } \\
\text { No }\end{array}$ & \\
\hline 0691 & 12 & $\begin{array}{l}\text { 散生 } \\
\text { Scattered }\end{array}$ & 31 & 59.55 & 56.72 & 1,160 & $\begin{array}{l}\text { 荒土 } \\
\text { Wasteland }\end{array}$ & $\begin{array}{l}\text { 未产种 } \\
\text { No }\end{array}$ & $\begin{array}{l}\text { 断梢 } \\
\text { Shoot break }\end{array}$ \\
\hline 0713 & 9 & $\begin{array}{l}\text { 散生 } \\
\text { Scattered }\end{array}$ & 25 & 54.14 & 19.63 & 1,100 & $\begin{array}{l}\text { 道路、河沟 } \\
\text { Road and river ditch }\end{array}$ & $\begin{array}{l}\text { 未产种 } \\
\text { No }\end{array}$ & \\
\hline 0723 & 12 & $\begin{array}{l}\text { 散生 } \\
\text { Scattered }\end{array}$ & 37 & 78.03 & 63.59 & 1,120 & $\begin{array}{l}\text { 黄连 } \\
\text { Coptis chinensis }\end{array}$ & $15.21 \mathrm{~g}$ & \\
\hline 0732 & 11 & $\begin{array}{l}\text { 散生 } \\
\text { Scattered }\end{array}$ & 20 & 31.53 & 12.56 & 1,120 & $\begin{array}{l}\text { 道路、河沟 } \\
\text { Road and river ditch }\end{array}$ & $\begin{array}{l}\text { 未产种 } \\
\text { No }\end{array}$ & \\
\hline 0735 & 10 & $\begin{array}{l}\text { 散生 } \\
\text { Scattered }\end{array}$ & 19 & 27.07 & 9.62 & 1,120 & $\begin{array}{l}\text { 道路、河沟 } \\
\text { Road and river ditch }\end{array}$ & $\begin{array}{l}\text { 未产种 } \\
\text { No }\end{array}$ & \\
\hline 0744 & 14 & $\begin{array}{l}\text { 集群 } \\
\text { Cluster }\end{array}$ & 39 & 45.86 & 78.50 & 1,170 & $\begin{array}{l}\text { 黄连 } \\
\text { Coptis chinensis }\end{array}$ & $\begin{array}{l}\text { 未产种 } \\
\text { No }\end{array}$ & \\
\hline 0745 & 11 & $\begin{array}{l}\text { 集群 } \\
\text { Cluster }\end{array}$ & 32 & 55.10 & 94.99 & 1,160 & $\begin{array}{l}\text { 山坡、河沟 } \\
\text { Hillside and river ditch }\end{array}$ & $\begin{array}{l}\text { 未产种 } \\
\text { No }\end{array}$ & \\
\hline 0791 & 10 & $\begin{array}{l}\text { 散生 } \\
\text { Scattered }\end{array}$ & 24 & 63.69 & 113.04 & 1,190 & $\begin{array}{l}\text { 水沟、油竹林 } \\
\text { Ditch and Bambusa } \\
\text { surrecta forest }\end{array}$ & $\begin{array}{l}\text { 未产种 } \\
\text { No }\end{array}$ & \\
\hline 0815 & 10 & $\begin{array}{l}\text { 集群 } \\
\text { Cluster }\end{array}$ & 43 & 92.36 & 63.59 & 1,100 & $\begin{array}{l}\text { 道路 } \\
\text { Road }\end{array}$ & $\begin{array}{l}\text { 未产种 } \\
\text { No }\end{array}$ & \\
\hline 0859 & 13 & $\begin{array}{l}\text { 散生 } \\
\text { Scattered }\end{array}$ & 28 & 61.78 & 28.26 & 1,140 & $\begin{array}{l}\text { 苗國地、房屋 } \\
\text { Nursery and house }\end{array}$ & $\begin{array}{l}\text { 未产种 } \\
\text { No }\end{array}$ & \\
\hline 0861 & 12 & $\begin{array}{l}\text { 散生 } \\
\text { Scattered }\end{array}$ & 26 & 46.50 & 23.75 & 1,140 & $\begin{array}{l}\text { 竹林 } \\
\text { Bamboo forest }\end{array}$ & $\begin{array}{l}\text { 未产种 } \\
\text { No }\end{array}$ & \\
\hline 0950 & 13 & $\begin{array}{l}\text { 集群 } \\
\text { Cluster }\end{array}$ & 38 & 78.03 & 44.16 & 1,170 & $\begin{array}{l}\text { 山林路边、荒地 } \\
\text { Mountain roadside and } \\
\text { wasteland }\end{array}$ & $\begin{array}{l}\text { 未产种 } \\
\text { No }\end{array}$ & \\
\hline 0956 & 10 & $\begin{array}{l}\text { 散生 } \\
\text { Scattered }\end{array}$ & 32 & 54.14 & 38.47 & 1,190 & $\begin{array}{l}\text { 水沟 } \\
\text { Ditch }\end{array}$ & $\begin{array}{l}\text { 未产种 } \\
\text { No }\end{array}$ & \\
\hline 0975 & 10 & $\begin{array}{l}\text { 散生 } \\
\text { Scattered }\end{array}$ & 24 & 64.01 & 33.17 & 1,140 & $\begin{array}{l}\text { 苗圃地 } \\
\text { Nursery }\end{array}$ & $\begin{array}{l}\text { 未产种 } \\
\text { No }\end{array}$ & $\begin{array}{l}\text { 断梢 } \\
\text { Shoot break }\end{array}$ \\
\hline 0981 & 15 & $\begin{array}{l}\text { 集群 } \\
\text { Cluster }\end{array}$ & 37 & 81.85 & 56.72 & 1,130 & $\begin{array}{l}\text { 黄连、水沟 } \\
\text { Coptis chinensis and ditch }\end{array}$ & $\begin{array}{l}\text { 未产种 } \\
\text { No }\end{array}$ & \\
\hline 0996 & 11 & $\begin{array}{l}\text { 散生 } \\
\text { Scattered }\end{array}$ & 37 & 69.11 & 50.24 & 1,140 & $\begin{array}{l}\text { 水沟 } \\
\text { Ditch }\end{array}$ & $\begin{array}{l}\text { 未产种 } \\
\text { No }\end{array}$ & $\begin{array}{l}\text { 断梢 } \\
\text { Shoot break }\end{array}$ \\
\hline 1005 & 13 & $\begin{array}{l}\text { 散生 } \\
\text { Scattered }\end{array}$ & 30 & 62.74 & 38.47 & 1,130 & $\begin{array}{l}\text { 金银花、土坎 } \\
\text { Lonicera japonica and ridge }\end{array}$ & $\begin{array}{l}\text { 未产种 } \\
\text { No }\end{array}$ & \\
\hline 1009 & 11 & $\begin{array}{l}\text { 散生 } \\
\text { Scattered }\end{array}$ & - & - & - & - & - & - & $\begin{array}{l}\text { 已死亡 } \\
\text { Dead }\end{array}$ \\
\hline 1011 & 10 & $\begin{array}{l}\text { 散生 } \\
\text { Scattered }\end{array}$ & 39 & 76.11 & 56.72 & 1,170 & $\begin{array}{l}\text { 水沟、道路 } \\
\text { Ditch and road }\end{array}$ & $0.36 \mathrm{~g}$ & \\
\hline 2415 & 10 & $\begin{array}{l}\text { 散生 } \\
\text { Scattered }\end{array}$ & 42 & 78.66 & 113.04 & 1,090 & $\begin{array}{l}\text { 房屋、竹林 } \\
\text { House and bamboo forest }\end{array}$ & $\begin{array}{l}\text { 未产种 } \\
\text { No }\end{array}$ & \\
\hline 2416 & 12 & $\begin{array}{l}\text { 散生 } \\
\text { Scattered }\end{array}$ & 33 & 78.34 & 63.59 & 1,090 & $\begin{array}{l}\text { 道路、牛圈 } \\
\text { Road and bought }\end{array}$ & $\begin{array}{l}\text { 未产种 } \\
\text { No }\end{array}$ & \\
\hline 2421 & 12 & $\begin{array}{l}\text { 散生 } \\
\text { Scattered }\end{array}$ & 29 & 84.39 & 188.60 & 1,120 & $\begin{array}{l}\text { 道路、柳杉 } \\
\text { Road and Cryptomeria } \\
\text { fortunei }\end{array}$ & $\begin{array}{l}\text { 未产种 } \\
\text { No }\end{array}$ & \\
\hline 4534 & 8 & $\begin{array}{l}\text { 集群 } \\
\text { Cluster }\end{array}$ & 30 & 76.43 & 44.16 & 1,103 & & $307.45 \mathrm{~g}$ & \\
\hline
\end{tabular}


表1 (续) Table 1 (continued)

\begin{tabular}{|c|c|c|c|c|c|c|c|c|c|}
\hline $\begin{array}{l}\text { 原始编号 } \\
\text { Mother } \\
\text { tree no. }\end{array}$ & $\begin{array}{l}\text { 包含等位 } \\
\text { 基因个数 } \\
\text { Number of } \\
\text { alleles* }\end{array}$ & $\begin{array}{l}\text { 分布特点 } \\
\text { Distribution } \\
\text { characteri- } \\
\text { stics }\end{array}$ & $\begin{array}{l}\text { 树高 } \\
\text { Tree } \\
\text { height } \\
\text { (m) }\end{array}$ & $\begin{array}{l}\text { 胸径 } \\
\text { Diameter at } \\
\text { breast height } \\
(\mathrm{cm})\end{array}$ & $\begin{array}{l}\text { 冠幅 } \\
\text { Crown } \\
\text { diameter } \\
\left(\mathrm{m}^{2}\right)\end{array}$ & $\begin{array}{l}\text { 海拔 } \\
\text { Altitude } \\
\text { (m) }\end{array}$ & $\begin{array}{l}30 \mathrm{~m} \text { 范围内环境因素 } \\
\text { Environmental factors } \\
\text { within } 30 \mathrm{~m}\end{array}$ & $\begin{array}{l}\text { 2017年产种量 } \\
\text { Yield in } 2017\end{array}$ & $\begin{array}{l}\text { 备注 } \\
\text { Remarks }\end{array}$ \\
\hline 4541 & 12 & $\begin{array}{l}\text { 集群 } \\
\text { Cluster }\end{array}$ & 30 & 105.73 & 50.24 & 1,153 & & $221.12 \mathrm{~g}$ & \\
\hline 4546 & 13 & $\begin{array}{l}\text { 散生 } \\
\text { Scattered }\end{array}$ & 30 & 123.25 & 153.86 & 1,036 & $\begin{array}{l}\text { 道路、河流、农田、蚁害 } \\
\text { Road, river, farmland and } \\
\text { ant harm }\end{array}$ & $\begin{array}{l}\text { 未产种 } \\
\text { No }\end{array}$ & $\begin{array}{l}10 \mathrm{~m} \text { 处分岔为两 } \\
\text { 株, 根部外露 } \\
\text { Two branches } \\
\text { at } 10 \mathrm{~m} \text {, with } \\
\text { exposed roots }\end{array}$ \\
\hline 4562 & 14 & $\begin{array}{l}\text { 集群 } \\
\text { Cluster }\end{array}$ & 31 & 74.84 & 38.47 & 1,363 & 河流 River & $\begin{array}{l}\text { 未产种 } \\
\text { No }\end{array}$ & \\
\hline 4566 & 14 & $\begin{array}{l}\text { 集群 } \\
\text { Cluster }\end{array}$ & 32 & 71.97 & 30.66 & 1,323 & 河流 River & $\begin{array}{l}\text { 未产种 } \\
\text { No }\end{array}$ & \\
\hline 5235 & 14 & $\begin{array}{l}\text { 集群 } \\
\text { Cluster }\end{array}$ & 32 & 56.37 & 33.17 & 998 & 水沟 Ditch & $\begin{array}{l}\text { 未产种 } \\
\text { No }\end{array}$ & \\
\hline 5581 & 12 & $\begin{array}{l}\text { 集群 } \\
\text { Cluster }\end{array}$ & 31 & 35.67 & 33.17 & 1,018 & $\begin{array}{l}\text { 水沟、农田 } \\
\text { Ditch and farmland }\end{array}$ & $\begin{array}{l}\text { 未产种 } \\
\text { No }\end{array}$ & \\
\hline 5590 & 13 & $\begin{array}{l}\text { 集群 } \\
\text { Cluster }\end{array}$ & 32 & 62.10 & 56.72 & 1,006 & $\begin{array}{l}\text { 房屋、道路、农田 } \\
\text { House, road, farmland }\end{array}$ & $\begin{array}{l}\text { 未产种 } \\
\text { No }\end{array}$ & \\
\hline 5614 & 15 & $\begin{array}{l}\text { 集群 } \\
\text { Cluster }\end{array}$ & 30 & 41.72 & 23.75 & 1,039 & & $\begin{array}{l}\text { 未产种 } \\
\text { No }\end{array}$ & \\
\hline 5618 & 16 & $\begin{array}{l}\text { 集群 } \\
\text { Cluster }\end{array}$ & 33 & 48.41 & 33.17 & 1,040 & & $\begin{array}{l}\text { 未产种 } \\
\text { No }\end{array}$ & \\
\hline 5637 & 13 & $\begin{array}{l}\text { 集群 } \\
\text { Cluster }\end{array}$ & 31 & 87.90 & 50.24 & 1,019 & $\begin{array}{l}\text { 房屋、道路、农田、蚁害 } \\
\text { House, road, farmland } \\
\text { and ant harm }\end{array}$ & $\begin{array}{l}\text { 未产种 } \\
\text { No }\end{array}$ & \\
\hline 5641 & 14 & $\begin{array}{l}\text { 集群 } \\
\text { Cluster }\end{array}$ & 27 & 57.32 & 44.16 & 1,067 & 水沟 Ditch & $\begin{array}{l}\text { 未产种 } \\
\text { No }\end{array}$ & \\
\hline 5685 & 14 & $\begin{array}{l}\text { 集群 } \\
\text { Cluster }\end{array}$ & 36 & 78.66 & 113.04 & 1,073 & 河流 River & $440.40 \mathrm{~g}$ & \\
\hline 5702 & 14 & $\begin{array}{l}\text { 集群 } \\
\text { Cluster }\end{array}$ & 31 & 52.87 & 23.75 & 1,040 & $\begin{array}{l}\text { 道路、河流、农田 } \\
\text { Road, river and farmland }\end{array}$ & $\begin{array}{l}\text { 未产种 } \\
\text { No }\end{array}$ & \\
\hline 5705 & 13 & $\begin{array}{l}\text { 集群 } \\
\text { Cluster }\end{array}$ & 29 & 42.04 & 15.90 & 1,043 & $\begin{array}{l}\text { 道路、河流、农田 } \\
\text { Road, river and farmland }\end{array}$ & $728.64 \mathrm{~g}$ & \\
\hline 5716 & 12 & $\begin{array}{l}\text { 集群 } \\
\text { Cluster }\end{array}$ & 29 & 49.04 & 19.63 & 1,061 & 水沟 Ditch & $\begin{array}{l}\text { 未产种 } \\
\text { No }\end{array}$ & \\
\hline 5741 & 15 & $\begin{array}{l}\text { 集群 } \\
\text { Cluster }\end{array}$ & 32 & 72.61 & 50.24 & 1,213 & 河流 River & $1,213.28 \mathrm{~g}$ & \\
\hline
\end{tabular}

* 数据由华东师范大学陈小勇教授提供 The data is provided by Professor Xiaoyong Chen of East China Normal University

表2７株水杉原生母树个体性状特征及繁殖特性

Table 2 Individual traits and reproductive characteristics of seven Metasequoia glyptostroboides original mother trees

\begin{tabular}{|c|c|c|c|c|c|}
\hline $\begin{array}{l}\text { 性状 } \\
\text { Traits }\end{array}$ & $\begin{array}{l}\text { 均值 } \pm \text { 标准差 } \\
\text { Mean } \pm \text { SD }\end{array}$ & $\begin{array}{l}\text { 最大值 } \\
\text { Max. }\end{array}$ & $\begin{array}{l}\text { 最小值 } \\
\text { Min. }\end{array}$ & $\begin{array}{l}\text { 变异系数 } \\
\text { Coefficient of variation (CV, \%) }\end{array}$ & $F$ \\
\hline 年龄 Age (yr) & $107.14 \pm 35.57$ & 160.00 & 75.00 & 33.19 & - \\
\hline 树高 Tree height (m) & $33.29 \pm 3.99$ & 39.00 & 29.00 & 11.99 & - \\
\hline 胸径 Diameter at breast height (cm) & $63.30 \pm 19.97$ & 123.25 & 27.07 & 29.96 & - \\
\hline 冠幅 Crown diameter $\left(\mathrm{m}^{2}\right)$ & $52.60 \pm 39.18$ & 188.60 & 9.62 & 69.38 & - \\
\hline 鲜果千粒重 Cone thousand-grain weight (g) & $2,592.58 \pm 617.62$ & $3,798.85$ & $1,957.90$ & 23.82 & - \\
\hline 种子千粒重 Seed thousand-grain weight (g) & $2.01 \pm 0.41$ & 2.56 & 1.47 & 20.40 & $22.402^{* * *}$ \\
\hline 发芽率 Sprouting percentage (\%) & $19.73 \pm 5.12$ & 26.67 & 10.56 & 25.95 & $19.144^{* * *}$ \\
\hline 存活率 Survival rate (\%) & $73.42 \pm 19.30$ & 100.00 & 44.11 & 26.29 & $4.539^{*}$ \\
\hline 基径 Base diameter (mm) & $1.51 \pm 0.27$ & 1.88 & 1.16 & 17.88 & $10.333^{* * *}$ \\
\hline 苗高 Seedling height (mm) & $130.27 \pm 18.80$ & 168.60 & 112.43 & 14.13 & 2.645 \\
\hline
\end{tabular}


效应，胸径增大，发芽率随之下降(表4)。

\section{3 幼苗生长节律参数}

不同母树个体苗高Logistic拟合方程的决定系 数为0.928-0.993 (表5), 说明该模型拟合值可信度 较高。7株母树幼苗的物候期参数存在差异(表6)。 不同母树个体苗高的速生期起止时间和持续时间 存在明显差异, 1011号母树开始时间和结束时间均 最晚, 4534号母树是最早进入线性生长期的, 也最早 结束。7株母树幼苗的苗高生长参数间也有差异, 但
差异程度不同，线性生长量占总生长量百分率的差 异小于最大线性生长速率和线性生长速率的差异。

不同母树个体幼苗基径Logistic拟合方程的决 定系数为0.983-0.993 (表7), 说明该模型拟合值可 信度较高。7株母树个体的幼苗基径物候期参数及 生长参数间有差异(表8), 不同母树线性生长期的起 止时间和持续时间不同，5741号母树最先进入线性 生长期，4534号母树最晚结束线性生长期，且线性 生长期持续时间最长。1011号母树最大线性生长速

表3 7株水杉原生母树性状与繁殖特性之间的相关性

Table 3 Correlation between maternal traits and reproductive characteristics of seven Metasequoia glyptostroboides original mother trees

\begin{tabular}{|c|c|c|c|c|c|c|c|c|c|c|}
\hline & $\begin{array}{l}\text { 年龄 } \\
\text { Age }\end{array}$ & $\begin{array}{l}\text { 树高 } \\
\text { Tree } \\
\text { height }\end{array}$ & $\begin{array}{l}\text { 胸径 } \\
\text { Diameter } \\
\text { at breast } \\
\text { height }\end{array}$ & $\begin{array}{l}\text { 冠幅 } \\
\text { Crown } \\
\text { diameter }\end{array}$ & $\begin{array}{l}\text { 鲜果千粒重 } \\
\text { Cone thousand- } \\
\text { grain weight }\end{array}$ & $\begin{array}{l}\text { 种子千粒重 } \\
\text { Seed thousand- } \\
\text { grain weight }\end{array}$ & $\begin{array}{l}\text { 发芽率 } \\
\text { Sprouting } \\
\text { percentage }\end{array}$ & $\begin{array}{l}\text { 存活率 } \\
\text { Survival } \\
\text { rate }\end{array}$ & $\begin{array}{l}\text { 基径 } \\
\text { Base } \\
\text { diameter }\end{array}$ & $\begin{array}{l}\text { 苗高 } \\
\text { Seedling } \\
\text { height }\end{array}$ \\
\hline 年龄 Age & 1 & & & & & & & & & \\
\hline 树高 Tree height & 0.494 & 1 & & & & & & & & \\
\hline 胸径 Diameter at breast height & 0.047 & 0.149 & 1 & & & & & & & \\
\hline 冠幅 Crown diameter & 0.120 & 0.643 & 0.534 & 1 & & & & & & \\
\hline $\begin{array}{l}\text { 鲜果千粒重 } \\
\text { Cone thousand-grain weight }\end{array}$ & -0.245 & 0.150 & -0.221 & 0.543 & 1 & & & & & \\
\hline $\begin{array}{l}\text { 种子千粒重 } \\
\text { Seed thousand-grain weight }\end{array}$ & -0.159 & 0.225 & -0.732 & 0.001 & 0.677 & 1 & & & & \\
\hline 发芽率 Sprouting percentage & -0.468 & -0.533 & $-0.843^{*}$ & -0.607 & 0.305 & 0.659 & 1 & & & \\
\hline 存活率 Survival rate & 0.403 & $0.852^{*}$ & 0.541 & 0.588 & -0.213 & -0.230 & $-0.786^{*}$ & 1 & & \\
\hline 基径 Base diameter & 0.449 & $0.878^{* *}$ & 0.146 & 0.308 & -0.186 & 0.148 & -0.459 & $0.866^{*}$ & 1 & \\
\hline 苗高 Seedling height & 0.236 & 0.718 & 0.012 & 0.232 & 0.041 & 0.396 & -0.238 & 0.562 & $0.818^{*}$ & 1 \\
\hline
\end{tabular}

$* P<0.05 ; * * P<0.01$

表4 水杉原生母树性状对种子发芽和幼苗生长的影响

Table 4 Effects of mother tree traits on seed germination and seedling growth of Metasequoia glyptostroboides original mother trees

\begin{tabular}{|c|c|c|c|c|c|c|c|c|c|c|c|c|}
\hline & \multicolumn{3}{|l|}{ 年龄 Age } & \multicolumn{3}{|c|}{ 树高 Tree height } & \multicolumn{3}{|c|}{ 胸径 Diameter at breast height } & \multicolumn{3}{|c|}{ 冠幅 Crown diameter } \\
\hline & $\begin{array}{l}\text { 回归系数 } \\
\text { Regression } \\
\text { coefficient }\end{array}$ & $\begin{array}{l}\text { 决定系数 } \\
\text { Determina- } \\
\text { tion coeffi- } \\
\text { cient }\end{array}$ & $P$ & $\begin{array}{l}\text { 回归系数 } \\
\text { Regression } \\
\text { coefficient }\end{array}$ & $\begin{array}{l}\text { 决定系数 } \\
\text { Determina- } \\
\text { tion coeffi- } \\
\text { cient }\end{array}$ & $P$ & $\begin{array}{l}\text { 回归系数 } \\
\text { Regression } \\
\text { coefficient }\end{array}$ & $\begin{array}{l}\text { 决定系数 } \\
\text { Determina- } \\
\text { tion coeffi- } \\
\text { cient }\end{array}$ & $P$ & $\begin{array}{l}\text { 回归系数 } \\
\text { Regression } \\
\text { coefficient }\end{array}$ & $\begin{array}{l}\text { 决定系数 } \\
\text { Determina- } \\
\text { tion coeffi- } \\
\text { cient }\end{array}$ & $P$ \\
\hline $\begin{array}{l}\text { 发芽率 } \\
\text { Sprouting } \\
\text { percentage }\end{array}$ & -0.14 & 0.06 & $>0.05$ & -0.82 & -1.41 & $>0.05$ & -0.48 & 0.65 & $<0.05$ & -2.89 & 0.24 & $>0.05$ \\
\hline $\begin{array}{l}\text { 存活率 } \\
\text { Survival } \\
\text { rate }\end{array}$ & 0.31 & 0.20 & $>0.05$ & 3.94 & 0.60 & $<0.05$ & 0.61 & 0.21 & $>0.05$ & 5.00 & 0.19 & $>0.05$ \\
\hline $\begin{array}{l}\text { 基径 } \\
\text { Base } \\
\text { diameter }\end{array}$ & 0.002 & -0.15 & $>0.05$ & 0.05 & 0.50 & $<0.05$ & 0.003 & -0.15 & $>0.05$ & 0.03 & -0.11 & $>0.05$ \\
\hline $\begin{array}{l}\text { 苗高 } \\
\text { Seedling } \\
\text { height }\end{array}$ & 0.02 & -0.20 & $>0.05$ & 1.41 & -0.09 & $>0.05$ & -0.37 & -0.05 & $>0.05$ & -1.45 & -0.16 & $>0.05$ \\
\hline
\end{tabular}


表5＼cjkstart不同水杉母树幼苗苗高生长曲线方程的拟合参数

Table 5 Parameters of height-logistic-equation of different Metasequoia glyptostroboides mother trees

\begin{tabular}{|c|c|c|c|c|c|c|}
\hline \multirow{2}{*}{$\begin{array}{l}\text { 母树编号 } \\
\text { Mother } \\
\text { tree no. }\end{array}$} & \multicolumn{6}{|c|}{ 拟合方程参数 Logistic equation parameters } \\
\hline & $\begin{array}{l}\text { 生长极限 } \\
\text { Growth limitation } \\
(k)\end{array}$ & $\begin{array}{l}\text { 待定系数 } \\
\text { Undetermined } \\
\text { coefficient }(a)\end{array}$ & $\begin{array}{l}\text { 待定系数 } \\
\text { Undetermined } \\
\text { coefficient }(b)\end{array}$ & $\begin{array}{l}\text { 决定系数 } \\
\text { Determination } \\
\text { coefficient }\left(R^{2}\right)\end{array}$ & $\begin{array}{l}\text { 检验值 } \\
\text { Levene }(F)\end{array}$ & $P$ \\
\hline 0723 & 481.375 & 4.633 & 0.037 & 0.991 & $1,283.823$ & 0.001 \\
\hline 1011 & 394.882 & 4.922 & 0.038 & 0.981 & 570.855 & 0.001 \\
\hline 4534 & 251.838 & 4.352 & 0.041 & 0.928 & 142.671 & 0.001 \\
\hline 4541 & 321.098 & 5.137 & 0.043 & 0.976 & 456.289 & 0.001 \\
\hline 5685 & 333.246 & 4.585 & 0.038 & 0.953 & 222.561 & 0.001 \\
\hline 5705 & 351.429 & 4.404 & 0.037 & 0.993 & $1,640.055$ & 0.001 \\
\hline 5741 & 318.744 & 4.126 & 0.036 & 0.937 & 165.176 & 0.001 \\
\hline
\end{tabular}

表6 不同水杉母树苗高的物候期参数和生长参数

Table 6 Phenophase and growth parameters of different Metasequoia glyptostroboides mother trees

\begin{tabular}{|c|c|c|c|c|c|c|c|}
\hline \multirow{2}{*}{$\begin{array}{l}\text { 母树编号 } \\
\text { Mother } \\
\text { tree no. }\end{array}$} & \multicolumn{3}{|c|}{ 物候期参数 Phenophase parameters } & \multicolumn{4}{|c|}{ 生长参数 Growth parameters } \\
\hline & $\begin{array}{l}\text { 线性生长始期 } \\
\text { Early stage of } \\
\text { linear growth (d) }\end{array}$ & $\begin{array}{l}\text { 线性生长末期 } \\
\text { Final stage of } \\
\text { linear growth (d) }\end{array}$ & $\begin{array}{l}\text { 线性生长期 } \\
\text { Stage of linear } \\
\text { growth (d) }\end{array}$ & $\begin{array}{l}\text { 最大线性生长速率 } \\
\text { The maximum } \\
\text { linear growth rate } \\
(\mathrm{mm} / \mathrm{d})\end{array}$ & $\begin{array}{l}\text { 平均线性生长速率 } \\
\text { Average linear } \\
\text { growth rate }(\mathrm{mm} / \mathrm{d})\end{array}$ & $\begin{array}{l}\text { 线性生长量 } \\
\text { Quantity of } \\
\text { linear } \\
\text { growth (mm) }\end{array}$ & $\begin{array}{l}\text { 线性生长量占总 } \\
\text { 生长量的百分率 } \\
\text { Linear growth as a } \\
\text { percentage of total } \\
\text { growth (\%) }\end{array}$ \\
\hline 0723 & 89.622 & 160.811 & 71.189 & 4.453 & 3.958 & 277.922 & 59.13 \\
\hline 1011 & 94.868 & 164.184 & 69.316 & 3.751 & 3.335 & 227.985 & 59.37 \\
\hline 4534 & 74.024 & 138.268 & 64.244 & 2.581 & 2.295 & 145.399 & 57.62 \\
\hline 4541 & 88.837 & 150.093 & 61.256 & 3.452 & 3.068 & 185.386 & 58.42 \\
\hline 5685 & 86.000 & 155.316 & 69.316 & 3.166 & 2.814 & 192.400 & 60.06 \\
\hline 5705 & 83.432 & 154.622 & 71.189 & 3.251 & 2.890 & 202.898 & 59.29 \\
\hline 5741 & 78.028 & 151.194 & 73.167 & 2.869 & 2.550 & 184.027 & 55.71 \\
\hline
\end{tabular}

表7 不同水杉母树幼苗基径生长曲线方程的拟合参数

Table 7 Parameters of base diameter-logistic-equation of different Metasequoia glyptostroboides mother trees

\begin{tabular}{|c|c|c|c|c|c|c|}
\hline \multirow{2}{*}{$\begin{array}{l}\text { 母树编号 } \\
\text { Mother } \\
\text { tree no. }\end{array}$} & \multicolumn{6}{|c|}{ 拟合方程参数 Logistic equation parameters } \\
\hline & $\begin{array}{l}\text { 生长极限 } \\
\text { Growth } \\
\text { limitation }(k)\end{array}$ & $\begin{array}{l}\text { 待定系数 } \\
\text { Undetermined } \\
\text { coefficient }(a)\end{array}$ & $\begin{array}{l}\text { 待定系数 } \\
\text { Undetermined } \\
\text { coefficient }(b)\end{array}$ & $\begin{array}{l}\text { 决定系数 } \\
\text { Determination } \\
\text { coefficient }\left(R^{2}\right)\end{array}$ & $\begin{array}{l}\text { 检验值 } \\
\text { Levene }(F)\end{array}$ & $\begin{array}{l}\text { 显著水平 } \\
\text { Significant } \\
\text { level }(P)\end{array}$ \\
\hline 0723 & 8.454 & 4.277 & 0.028 & 0.983 & 634.530 & 0.001 \\
\hline 1011 & 8.097 & 5.496 & 0.038 & 0.993 & $1,491.536$ & 0.001 \\
\hline 4534 & 5.286 & 3.280 & 0.019 & 0.981 & 581.010 & 0.001 \\
\hline 4541 & 5.318 & 4.152 & 0.030 & 0.987 & 832.258 & 0.001 \\
\hline 5685 & 4.356 & 4.672 & 0.037 & 0.985 & 716.288 & 0.001 \\
\hline 5705 & 3.769 & 3.739 & 0.029 & 0.992 & $1,343.069$ & 0.001 \\
\hline 5741 & 3.702 & 3.565 & 0.029 & 0.988 & 915.982 & 0.001 \\
\hline
\end{tabular}

率与平均线性生长速率最大，其次是 0723 号母树。

苗高的线性生长期结束时间均比基径早，除 5741 号母树的基径进入线性生长期的时间略早于 苗高外，其余母树的基径进入线性生长期的时间均 比苗高晚(表6,8)。水杉幼苗的苗高和基径在一年的 生长周期内, 线性生长量占总生长量的百分率达到
55\%以上，说明线性生长期是年生长周期过程中非 常重要的时期。但从水杉幼苗苗高和基径的线性生 长期的持续时间来看，基径的线性生长期持续时间 高于苗高, 这表明水杉幼苗的苗高停止生长之后, 基径还处于生长状态。不同母树苗高、基径的 Logistic拟合曲线见图1和图2。 
表8 不同水杉母树基径的物候期参数和生长参数

Table 8 Phenophase and base diameter parameters of different Metasequoia glyptostroboides mother trees

\begin{tabular}{|c|c|c|c|c|c|c|c|}
\hline \multirow{2}{*}{$\begin{array}{l}\text { 母树编号 } \\
\text { Mother } \\
\text { tree no. }\end{array}$} & \multicolumn{3}{|c|}{ 物候期参数 Phenophase parameters } & \multicolumn{4}{|c|}{ 生长参数 Growth parameters } \\
\hline & $\begin{array}{l}\text { 线性生长始期 } \\
\text { Early stage of } \\
\text { linear growth (d) }\end{array}$ & $\begin{array}{l}\text { 线性生长末期 } \\
\text { Final stage of } \\
\text { linear growth (d) }\end{array}$ & $\begin{array}{l}\text { 线性生长期 } \\
\text { Stage of linear } \\
\text { growth (d) }\end{array}$ & $\begin{array}{l}\text { 最大线性生长速率 } \\
\text { The maximum linear } \\
\text { growth rate }(\mathrm{mm} / \mathrm{d})\end{array}$ & $\begin{array}{l}\text { 平均线性生长速率 } \\
\text { Average linear } \\
\text { growth rate }(\mathrm{mm} / \mathrm{d})\end{array}$ & $\begin{array}{l}\text { 线性生长量 } \\
\text { Quantity of } \\
\text { linear } \\
\text { growth (mm) }\end{array}$ & $\begin{array}{l}\text { 线性生长量占总 } \\
\text { 生长量的百分率 } \\
\text { Linear growth as a } \\
\text { percentage of total } \\
\text { growth (\%) }\end{array}$ \\
\hline 0723 & 105.714 & 199.786 & 94.071 & 0.059 & 0.053 & 4.881 & 63.23 \\
\hline 1011 & 109.974 & 179.289 & 69.316 & 0.077 & 0.068 & 4.675 & 60.95 \\
\hline 4534 & 103.316 & 241.947 & 138.632 & 0.025 & 0.022 & 3.052 & 79.07 \\
\hline 4541 & 94.500 & 182.300 & 87.800 & 0.040 & 0.035 & 3.070 & 60.79 \\
\hline 5685 & 90.676 & 161.865 & 71.189 & 0.040 & 0.036 & 2.515 & 58.90 \\
\hline 5705 & 83.517 & 174.345 & 90.828 & 0.027 & 0.024 & 2.176 & 62.17 \\
\hline 5741 & 77.517 & 168.345 & 90.828 & 0.027 & 0.024 & 2.137 & 60.88 \\
\hline
\end{tabular}
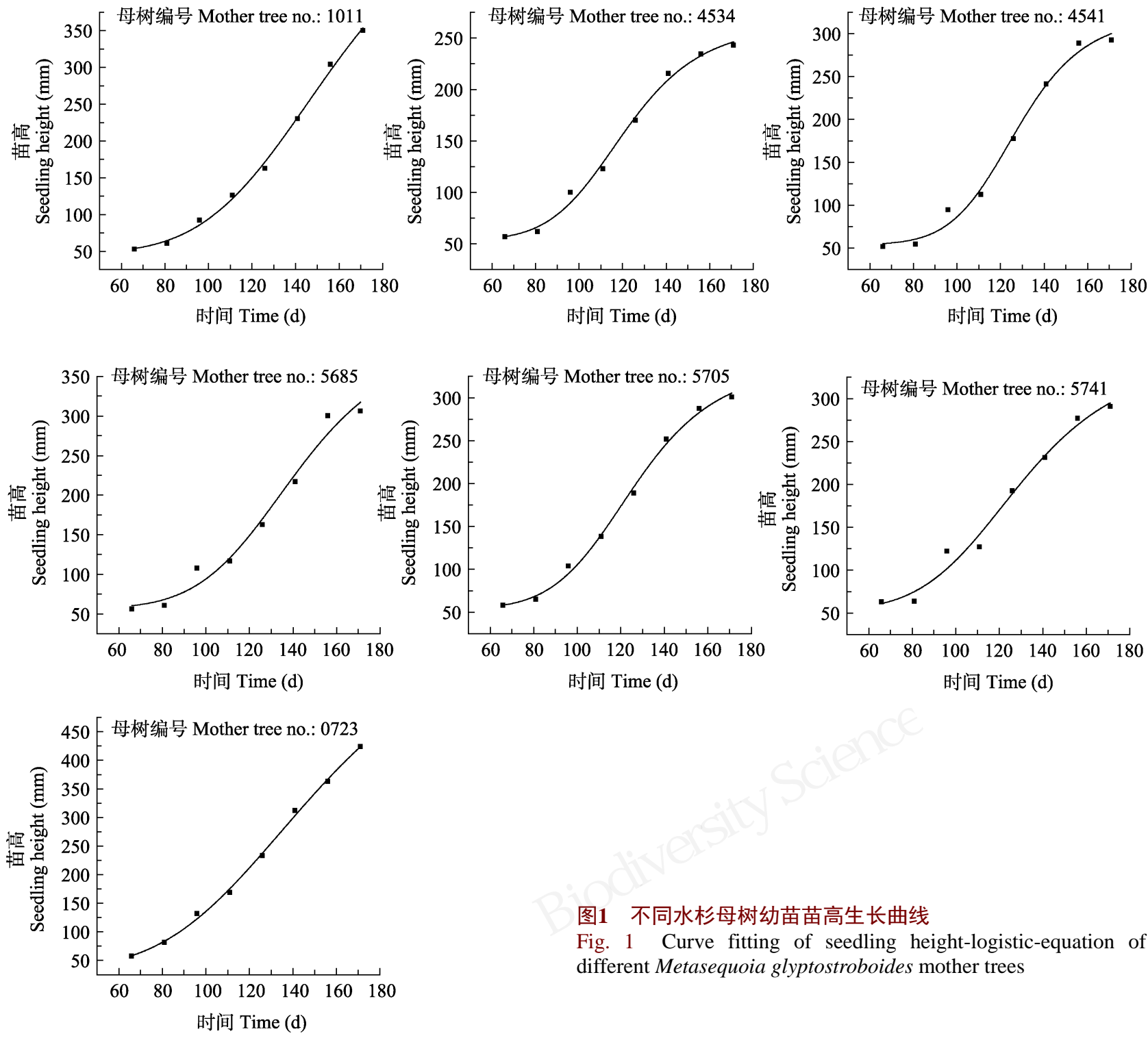

图1 不同水杉母树幼苗苗高生长曲线

Fig. 1 Curve fitting of seedling height-logistic-equation of different Metasequoia glyptostroboides mother trees 

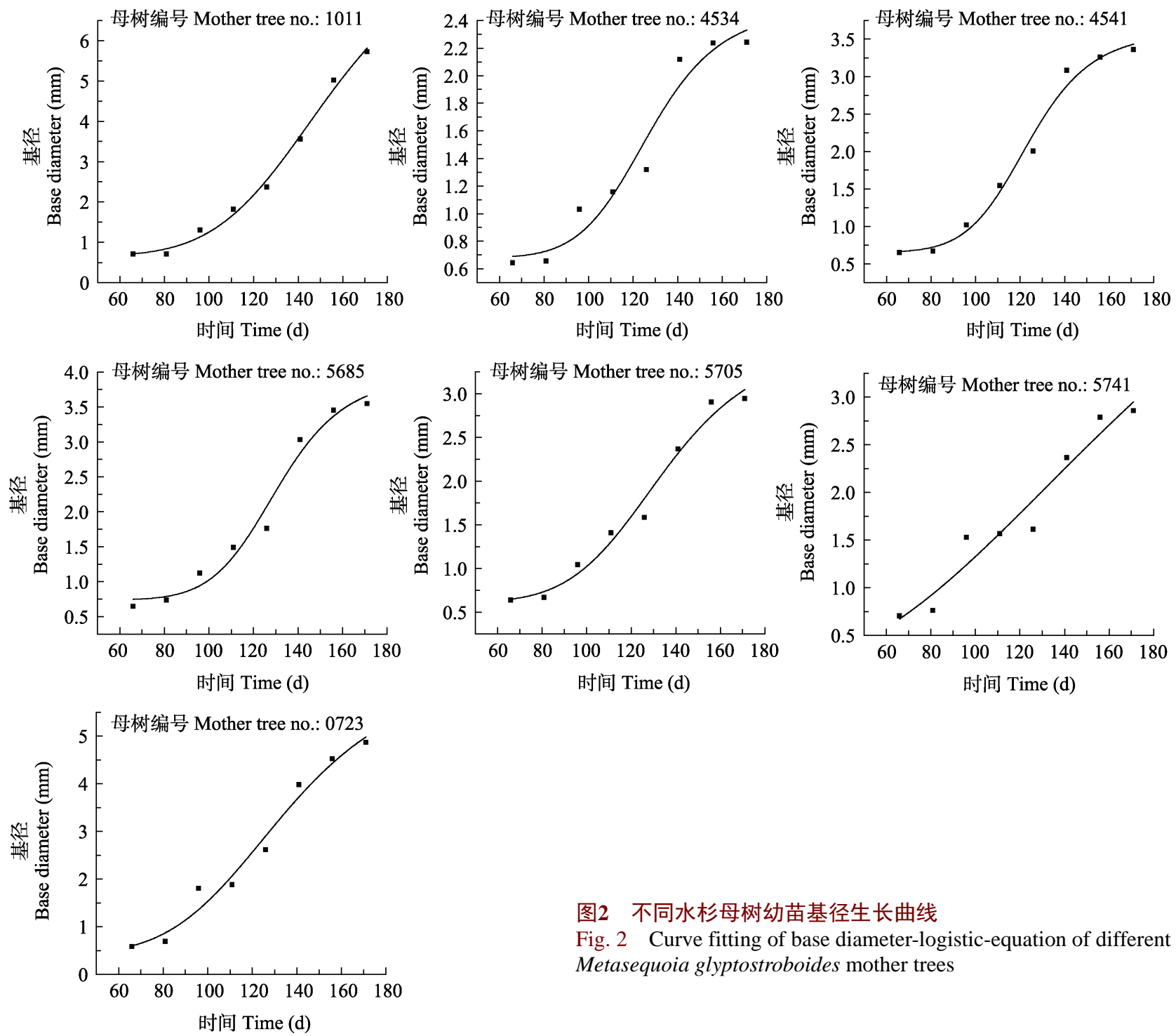

图2 不同水杉母树幼苗基径生长曲线

Fig. 2 Curve fitting of base diameter-logistic-equation of different Metasequoia glyptostroboides mother trees

\section{3 讨论}

\subsection{7 株核心种质资源母树繁殖特性的差异}

本研究调查发现 40 株核心种质资源原生母树 只有7株产种, 产种率低且产种量小。结合王希群 (1994)研究发现水杉母树产种呈现“丰_平-歉-歉” 的年际变化趋势, 产种量年际间变化较大。说明水 杉原生种群产种量小且不稳定, 水杉原生种群产种 量低可能是造成其天然更新困难的原因。余诚棋等 (2010)认为林木变异存在多种模式, 在不同母树个 体和家系水平上不同性状变异差异较大。本研究通 过实验发现种子发芽率低, 仅为 $19.73 \%$, 变异系数 为 $25.95 \%$, 说明水杉种子质量差, 不同母树之间繁 殖变异明显。这可能与水杉花器官成熟较晚且雌雄 器官成熟时间不一致有关。雄花花期晚于雌花花期,

导致产生有胚种子的概率较低, 而有胚种子少直接 影响了种子发芽率。

\section{2 母树个体性状对繁殖特性的影响}

研究发现，原生母树的4个个体性状中，树高 对幼苗的存活率和基径生长有显著的正效应，树高 增加, 幼苗的存活率和基径也随之增加，母树胸径 对种子发芽率有显著负效应，胸径增大，发芽率随 之下降。母树年龄、平均冠幅对种子发芽和幼苗存 活与生长没有显著影响。郭洪岭等(2014)研究影响 黄连木(Pistacia chinensis)果实产量和种子命运的因 素时发现，树高与果实产量呈正相关，说明较高的 个体比较低的个体对繁殖更有利，这可能与母树生 长活力有关, 偏于向上生长的母树可能生活力更旺 盛，能接触到更多阳光、更易于受粉，所以能够产 
生更多高质量的种子。本研究调查的原生母树胸径 变幅主要集中在27.07-123.25 cm之间, 只有3株母 树胸径低于 $40 \mathrm{~cm}$, 因此, 水杉原生种群母树胸径 过大可能是导致水杉种子质量差的重要因素。水杉 母树树高对于幼苗的存活率和基径生长的正效应, 有利于指导人工培育水杉时进行优树优种选择。本 研究还发现5741号母树产种量高, 但发芽率较低, 且幼苗生长较差; 1011号母树产种量低, 发芽率低, 但幼苗存活率高, 幼苗生长指标良好。综合考虑, 5705 号母树产种量高, 发芽率高, 是栽培育苗的良 好种源选择。

\section{3 水杉幼苗生长节律参数}

生长表型性状是最直观、最能反映苗木总体长 势的易测定指标(王琦和朱之悌，1995)。“S”型生长 曲线可以用于描述某一种群受空间约束的生长过 程(卢恩双等, 2002), 其特点是开始生长缓慢, 随着 环境条件的变化, 某一时间段内生长速度加快, 接 近线性生长, 达到一定界限之后, 生长速度又趋于 缓慢, 直至生长停止(杨志玲等, 2011)。“S”型生长曲 线动态和变化规律已在林木生长的研究中得到了 广泛验证(洪伟等, 2004; 麻文俊等, 2010)。水杉幼 苗苗高在一年内线性生长期内的生长量占总生长 量的 $55.71 \%-60.06 \%$, 基径在一年内线性生长量占 总生长量的 $58.90 \%-79.07 \%$ 。杨志玲等(2011)研究了 厚朴(Magnolia officinalis)幼苗生长节律参数, 发现 厚朴苗期苗高线性生长量占总生长量的 58.03\%61.73\%, 基径线性生长量占总生长量的 63.01\%$79.41 \%$ 。水杉幼苗的线性生长量占总生长量的百分 比相较于厚朴略低。线性生长期是符合“S”型生长 曲线的苗木的关键时期, 这一阶段苗木的生长量对 于整个生长量起着至关重要的作用。因此, 在水杉 播种育苗的实践过程中, 要重点把握这一生长阶段, 做好追肥、锄草、病虫害防治等工作。在线性生长 期结束后, 幼苗回到缓慢生长的阶段, 此阶段重点 在于促进苗木木质化, 以提高育苗成活率。另外, 水杉幼苗苗高生长持续时间均小于基径生长持续 时间, 因此, 基径可以作为在育苗过程中判断幼苗 是否进入休眠的判定标准之一。

\section{参考文献}

Chu KL, Cooper WS (1950) An ecological reconnaissance in the native home of Metasequoia glyptostroboides. Ecology,
31, 260-278.

Guo HL, Li ZW, Xiao ZS (2014) Factors influencing the fruit crops and seed fates of Pistacia chinensis: The results of structural equation modeling. Biodiversity Science, 22, 174-181. (in Chinese with English abstract) [郭洪岭, 李志 文, 肖治术 (2014) 应用结构方程模型解析影响黄连木 果实产量和种子命运的因素. 生物多样性, 22, 174-181.]

Guo QJ, Wang ZM, Deng ZZ (2018) Influences of different sodium selenite concentrations on seed germination of Metasequoia glyptostroboides. Guihaia, 38, 1319-1325. (in Chinese with English abstract) [郭秋菊, 王志鸣, 邓桢珍 (2018) 不同浓度亚硒酸钠溶液对水杉种子萌发的影响. 广西植物, 38, 1319-1325.]

Hong W, Wu CZ, Yan SJ (2004) Modification of population growth model. Chinese Journal of Applied and Environmental Biology, 22, 23-26. (in Chinese with English abstract) [洪伟, 吴承祯, 间淑君 (2004) 对种群增长模型的改进. 应用与环境生物学报, 22, 23-26.]

Hu XS, Zheng WJ (1948) On the new family Metasequoiaceae and on Metasequoia glyptostroboide, a living species of the genus Metasequoia found in Szechuan and Hupen. Bulletin of the Fan Memorial Institute of Biology, 1, 153-161. (in Chinese with English abstract) [胡先骕, 郑万钧 (1948) 水 杉新科及生存之水杉新种. 静生生物调查所汇报, 1 , 153-161.]

Jing DL, Liang HW, Wang YB, Wang J, Zhang DC (2011) Influence of different light and storage temperature on germination rate and enzyme activities of Metasequoia glyptostroboide seeds. Hubei Agricultural Sciences, 50, 3980-3983. (in Chinese with English abstract) [景丹龙, 梁宏伟, 王玉 兵, 王静, 张德春 (2011) 不同光照及储藏温度对水杉种 子萌发及酶活性的影响. 湖北农业科学, 50, 3980-3983.]

Kuser JE, Sheely DL, Hendricks DR (1997) Genetic variation in two ex situ collections of the rare Metasequoia glyptostroboides (Taxodiaceae). Silvae Genetica, 46, 258-264.

Li JH, Ban JD (1989) Specialty populations of Metasequoia glyptostroboides in China. Journal of Henan Normal University (Natural Science), (4), 49-55. (in Chinese with English abstract) [李建华, 班继德 (1989) 中国特产的水杉群落. 河南师范大学学报(自然科学版), (4), 49-55.]

Li FQ, Chen HW, Zhou ZC, Chu XL, Xu ZY, Xiao JJ (2018) Analysis on variation of seed and seedling traits of superior trees of Ormosia hosiei and primary screening of optimum family. Journal of Plant Resources and Environment, 27, 57-65. (in Chinese with English abstract) [李峰卿, 陈焕伟, 周志春, 楚秀丽, 徐肇友, 肖纪军 (2018) 红豆树优树种 子和幼苗性状的变异分析及优良家系的初选. 植物资源 与环境学报, 27, 57-65.]

Li QM, Xie ZQ, Sun YL (2008) Study on seedling adaptability of Abies chensiensis. Forest Research, 21, 481-485. (in Chinese with English abstract) [李庆梅, 谢宗强, 孙玉玲 (2008) 秦岭冷杉幼苗适应性的研究. 林业科学研究, 21, 481-485.] 
Li XD, Huang HW, Li JQ (2003) Genetic diversity of the relict plant Metasequoia glyptostroboides. Biodiversity Science, 11, 100-108. (in Chinese with English abstract) [李晓东, 黄宏文, 李建强 (2003) 子遗植物水杉的遗传多样性研 究. 生物多样性, 11, 100-108.]

Li YY (2006) Phylogenetic Position and Recovery Assessment of Metasequoia glyptostroboides. PhD dissertation, East China Normal University, Shanghai. (in Chinese with English abstract) [李媛媛 (2006) 水杉的系统发育地位及恢复 评价. 博士学位论文, 华东师范大学, 上海.]

Lin Y, Ai XR, Yao L, Guo QJ, Zhang MX, Chen J (2017) Population structure and dynamics of Metasequoia glyptostroboides parent trees. Chinese Journal of Ecology, 36, 15311538. (in Chinese with English abstract) [林勇, 艾训儒, 姚 兰, 郭秋菊, 张敏霞, 陈俊 (2017) 水杉原生母树种群结 构与动态. 生态学杂志, 36, 1531-1538.]

Lu ES, Guo MC, Song SD, Yuan ZF (2002) A kind of nonautonomous Logistic growth curve and its application. Journal of Northwest A \& F University (Natural Science Edition), 30(4), 127-129. (in Chinese with English abstract) [卢恩双, 郭满才, 宋世德, 袁志发 (2002) 一类非自治的Logistic 生长曲线及其应用. 西北农林科技大学学报(自然科学 版), 30(4), 127-129.]

Ma WJ, Wang JH, Zhang SG, Zhang JG, Zhao K, Jiao YD (2010) Analysis of annual growth parameters for Catalpa bungei clones at seedling stage. Journal of Northeast Forestry University, 38(1), 4-7, 11. (in Chinese with English abstract) [麻文俊, 王军辉, 张守攻, 张建国, 赵鲲, 焦云德 (2010) 楸树无性系苗期年生长参数的分析. 东北林业大 学学报, 38(1), 4-7, 11.]

She CQ, Yang WX, Fang SZ, Shang XL (2010) Variation analysis of seedling characters among provenances of Cyclocarya paliurus. Journal of Nanjing Forestry University (Natural Sciences Edition), 34(1), 34-38. (in Chinese with English abstract) [余诚棋, 杨万霞, 方升佐, 尚旭岗 (2010) 青钱柳种源间苗期性状变异分析. 南京林业大学 学报(自然科学版), 34(1), 34-38.]
Wang Q, Zhu ZT (1995) Study on correlate selection from plus clones of Populus tomentosa. Forest Research, 8, 107-111. (in Chinese with English abstract) [王琦, 朱之悌 (1995) 毛白杨优树无性系相关选择研究. 林业科学研究, 8, 107-111.]

Wang XQ (1994) Production route of Metasequoia seeds. Seed, (1), 41. (in Chinese) [王希群 (1994) 水杉种子的生产途 径. 种子, (1), 41.]

Xin X, Jing XM, Sun HM, Lin J, Wang XF (2004) Ecophysiological characteristics of seed germination of the relict plant Metasequoia glyptostroboide. Biodiversity Science, 12, 572-577. (in Chinese with English abstract) [辛霞, 景 新明, 孙红梅, 林坚, 汪晓峰 (2004) 子遗植物水杉种子 萌发的生理生态特性研究. 生物多样性, 12, 572-577.]

Yang ZL, Yang X, Tan ZF, Shu X, Wang J, Tan GY (2011) Simulating growth model of different Magnolia officinalis provenances at seedling stage. Journal of Northwest A \& F University (Natural Science Edition), 39(4), 60-68. (in Chinese with English abstract) [杨志玲, 杨旭, 谭梓峰, 舒 系, 王洁, 檀国印 (2011) 厚朴不同种源苗期生长模型的 拟合. 西北农林科技大学学报 (自然科学版), 39(4), 60-68.]

You DM, Ma GL (2008) Effects of different litter layer depth on seed germination of Metasequoia glyptostroboides. Journal of Nanyang Normal University, (6), 51-53. (in Chinese with English abstract) [尤冬梅, 马广礼 (2008) 水杉枯落 物对其种子萌发的影响初探. 南阳师范学院学报, (6), 51-53.]

You DM, Wang ZX, Lei Y, Ma GL (2008) Community classification and dynamics succession of natural forest of Metasequoia glyptostroboides Hu et Cheng. Hubei Forestry Science and Technology, (5), 6-11. (in Chinese with English abstract) [尤冬梅, 汪正祥, 雷耘, 马广礼 (2008) 天然水杉林的群落分类及演替动态. 湖北林业科技, (5), 6-11.]

(责任编委: 藏润国 责任编辑: 问文杰) 